\title{
FLUOTHANE-ETHER IN ANAESTHESIA FOR PULMONARY SURGERY
}

\author{
J.-P. Dechê̂NE, M.D., and Claude Hébert, M.D. ${ }^{1}$
}

SINCE THE BEGINNing of February, 1958, the Fluothane-ether azeotropic mixture has been used with satisfaction in the Department of Anaesthesia of Laval Hospital. By the end of April, 1959, we had used it in 241 pulmonary surgical cases, in patients of various ages, using different machines and techniques. The sole aim of this summary is to describe our clinical experience with Fluothane-ether, especially in pulmonary anaesthesia, and -hen to show the numerous advantages of the method which, at least in our hal-!ds, has lielped to reduce surgical and anaesthetic hazards.

\section{General Consmerations}

The combination of volatile anaesthetics is well known, especially to practising physicians. Although they are not perfect, the combinations of ethyl chloride and ether, Vinethene and ether, and especially chloroform and ether, are still used' in daily medical practice. However, in modern hospital centres, where specialists work together in the departments of anaesthesia, suitable anaesthetic mixtures are required and desirable. Thanks to Professor Fernando Hudon and his colleagues we have the ideal volatile anaesthetic mixture called Fluothane-ether azeotropic mixture, which is composed of ether 31.7 vol. per cent, Fluothane 68.3 vol. per cent, with a common boiling point of $51.5^{\circ} \mathrm{C}$., having a concomitant action. The clinical results obtained with this new mixture have proved very interesting in general surgery. According to the authors, "an improved anaesthesia which should be more and more used in the future" is obtained. At Laval Hospital, in an endeavour to improve our anaesthetic techniques and to investigate it further, we have undertaken the use of this azeotropic mixture in pulmonary and cardiac surgery. The cardiovascular studies in dogs had been encouraging, and our first clinical tests in pulmonary surgery being successful and stimulating, this modern method of anaesthesia has become a daily practice, especially in pulmonary surgery.

\section{Clinical Experience}

\section{Statistics}

As mentioned above, the Fluothane-ether azeotropic mixture was used (between February 1, 1958, and April 15, 1959) at Laval Hospital in 241 cases of pulmonary surgery. We carried out a total of 192 pulmonary resections, including 25 segmentectomies, 114 lobectomies, and 53 pneumonectomies.. Moreover, there

1Department of Anaesthesia, Laval Hospital 
were 18 thoracoplasties, and 31 cases of bronchial aspirations and bronchographies (13) and costotomies (18). The patients varied in age from 2 to 69 years, the average age being 27 years.

\section{Technique of Anaesthesia}

It is a habit in our group to use a potent and mixed premedication: on the previous evening, a non-barbiturate hypnotic, Noludar ${ }^{\circledR}$ combined with the antihistamine Phenergan ${ }^{\circledR}$; in the morning, Phenergan again and, about one hour before the operation, morphine and atropine. The dosages are adjusted according to age, weight, and condition of the patient. Induction is carried out with thiopental and a short-acting muscle relaxant of the succinylcholine-type is used to facilitate endoscopy, intubation, and bronchoscopic aspiration if required. Anaesthetic maintenance is effected with Fluothane-ether, administered and vaporized. with nitrous oxide-oxygen $(50 / 50)$ and, when required, muscle-relaxant drip (succinylcholine-type) is administered at 0.1 per cent or 0.2 per cent to obtain a "balanced anaesthesia." At the beginning and in resistant patients, anaesthesia was potentiated by combining Nisentil ${ }^{\circledR}$ and Lorfan ${ }^{\circledR}$ or Leritine ${ }^{\circledR}$ and Lorfan. However, in view of the analgesic potency of Fluothane-ether which is becoming more evident, we use less and less potentiation, and now it is only used for immediate premedication, intravenously, or for postoperative sedation in the recovery room.

\section{Duration of Anaesthesia}

In pulmonary surgery, it is well known that operations generally last much longer than in ordinary general surgery, resections lasting about three hours and sometimies more.

\section{Anaesthetic Equipment}

The anaesthetic machines generally used are two types: the Boyle's and the Heidbrink.

The Fluothane-ether mixture was first used in the ether bottle of the 'Boyle's machine in open or semi-open circle ( 10 patients), and also in the No. 7 vaporizer of the Heidbrink machine ( 2 patients) only in semi-open circle. A high flow, 6-8 L. of nitrous oxide and oxygen $(50 / 50)$, was used for the vaporization of the volatile agents. We soon obtained a Fluotec vaporizer and we used it with the Boyle's machine for the majority of our cases (about 149). The Fluotec is an excellent vaporizer for Fluothane, its main advantage-being the precision of vaporization. We shall talk about this subject later. The Vernitrol vaporizer of the new Heidbrink machine was also used in 80 cases. The Vernitrol system vaporizes the Fluothane-ether mixture at a high and uniform concentration. This concentration is, however, too high to be administered to the patient and, for this reason, with the help of a nomogram, we calculate the flow of nitrous oxide and oxygen necessary for the dilution of our volatile mixture. Finally, we were able to read on the Vernier scale the volume of gas administered to the patient, of Fluothane-ether as well as nitrous oxide-oxygẹn; (this is the reason for the name Vernitrol ). When the quantity of nitrous oxide-oxygen is insufficient, the Vernitrol 
vaporizer can deliver to the patient dangerous and even lethal concentrations of Fluothane-ether which is a serious disadvantage. Our clinical experience with the Fluothane vaporizers corroborates that of Drs. MacKay and Kalow of Toronto (4) who stated that: "The Fluotec possesses great precision and consequently this vaporizer presents greater safety and efficacy." Its compensating mechanism for the control of temperature and gas flow in the semi-open as well as open circle provides precision and gives excellent results. Moreover, for safe administration and a more precise Fluothane-ether vaporization, it is important to attach the vaporizer to the anaesthetic machine between the control valve and the circle inlet and not inside the circle itself. In doing this, the Fluothane-ether and the nitrous oxide-oxygen vapour always remain the same and do not vary with the patient's ventilation.

\section{Cardiac and General Surgery}

In addition to the above-mentioned pulmonary surgery cases, we also used the Fluothane-ether mixture in 19 cases of cardiac surgery (such as arterial shunts, coarctation of the aorta, pericardial cyst, and mitral commissurotomy), and in 152 cases of general surgery (such as arthrodesis, Albee's graft, appendectomy, cholecystectomy, incision of abscesses, tonsillectomy, nephrectomy, and in obstetrics).

\section{Jefferson Respiratory Ventilator}

In all patients, a total of 394, breathing was assisted by manual control or with the aid of the Jefferson ventilator, with or without negative pressure, as required.

\section{Discussion, Results, and Conclusions}

\section{Discussion and Results}

From the beginning, we have indicated the great satisfaction we obtained with the Fluothane-ether azeotropic mixture in pulmonary surgery especially for the following reasons: (i) safety of the azeotropic mixture from the cardiorespiratory aspect; (ii) the practical use of this anaesthetic method in pulmonary surgery.

From the respiratory viewpoint. A 1.5 per cent inhaled vapour concentration suffices to maintain anaesthesia. Consequently, in pulmonary surgery where one nearly always encounters some difficulty with oxygenation, the azeotropic mixture provides a more than satisfactory oxygen saturation. Moreover, the bronchodilator effect improves our patients' ventilation which is often reduced due to their respiratory disease. In this series of cases, no patient showed any serious anoxia or even hypoxia during surgery. In summarizing, let us say that with Fluothane-ether no respiratory difficulty occurs, whereas Fluothane alone reduces the respiratory minute rate. Postoperatively, atelectasis was reduced to a minimum.

From the cardiovascular viewpoint. Another safety feature of the Fluothaneether mixture lies in the fact that; contrary to the use of Fluothane alone, it does 
not seem to affect our patients; , cardiovascular function, at least in light anaesthesia. This is our personal clinical experience and was proved in experiments on dogs. A hypotension of $20-30-40 \mathrm{~mm}$. $\mathrm{Hg}$ was seen only in deep anaesthesia, which is not at all necessary in pulmonary surgery. Likewise, in light anaesthesia, arrhythmias seldom appear on the electrocardiogram and consist only of a few extrasystoles when they do. Our previous studies on dogs showed that the cardiac output is practically unaffected in light anaesthesia. In the same series there was absolutely no cardiovascular disturbance with the exception of a few extrasystoles on electrocardiogram and a slight hypotension of about $10 \mathrm{~mm}$. $\mathrm{Hg}$. As was emphasized by the authors of this method, the ether fraction which stimulates respiration and circulation makes the mixture twice as safe from the cardiorespiratory viewpoint.

Practicability of this anaesthetic method. The second reason for our satisfaction with the Fluothane-ether in anaesthesia for pulmonary surgery is its cardiorespiratory safety. The mixture can be administered in any pulmonary case with the possible exception of certain bronchial fistulas where inhalation anaesthesia is contraindicated because it would mean the induction of anaesthetic gases into an already perforated tube. Moreover, since Fluothane renders the mixture nonflammable, the use of the electric cautery or bistoury is facilitated, an undeniable advantage in pulmonary surgery. Consequently, this method is essentially practical:

\section{Conclusion}

After using the azeotropic Fluothane-ether mixture in anaesthesia for pulmonary surgery on patients of various ages, for different kinds of operations, with various anaesthetic machines and different techniques, we are extremely satisfied with the results and we believe we are justified in recommending this new anaesthetic technique for pulmonary surgery to our confrères.

\section{REFERENCES}

1. Hudon, F., Jacoues, A., \& Borvin, P. A. Fluothane-éther mélange azéotrope. Laval Méd. 25 (5): 607-614 (Nay, 1958).

2. DechÊNe, J.-P. Etudes cardio-vasculaires sur le Fluothane-éther. Travail présenté à l'Ecole de Médecine de l'Université Laval, lors de la Journée Scientifique de la Société Canadienne d'Anesthésie, le 31 janvier 1959 (à être publié).

3. Dechêne, J.-P. Communication personnelle à la Compagnie Ayerst-McKenna sur nos premiers essais en chirurgie pulmonaire (mars 1958).

4. MacKay, Iain M., \& Kalow, Werner. A Clinical and Laboratory Evaluation of Four Fluothane Vaporizers. Canad. Anaesth. Soc. J. 5: 248-261 (July, 1958).

5. Long, J.-P., Pithinger, C. B., \& Hamilton, W. K. Laboratory Studies on the Cardiovascular and Respiratory Effects of Fluothane. Anesth. \& Analg. 37: 355-360 (Nov.Dec., 1958).

6. Dobkin, Allen B. Circulatory Dynamics during Light Halothane Anaesthesia. Brit. J. Anaesth. 30: 568-577 (Dec., 1958)!'

․ Fabien, W.; Stephen, C. R.; Bourgeois-Gavarpin, M.; \& Dent, S، J. Performance Characteristics of Vaporizers for Administration of Fluothane. Anesthesiology, p. 2 (Jan.-Feb., 1959). 